\title{
Modelling of the Central Heating Station within a District Heating System with Variable Temperatures
}

\author{
Tobias Ramm $^{1} \quad$ Mathias Ehrenwirth $^{1} \quad$ Tobias Schrag $^{1}$ \\ ${ }^{1}$ Institut für Neue Energie-Systeme, Technische Hochschule Ingolstadt, Germany \\ Tobias.Rammethi.de
}

\begin{abstract}
Within this paper, the concept of developing a detailed model for an existing district heating system (DHS) is described. The research focusses on the central heating station with multiple different supply units. In the present case, the model is implemented with a close-toreality-control and will be used for testing new control strategies for the DHS. Therefore, a model with both realistic behavior as well as control interfaces similar to the real control is necessary. Within the NATAR research project (Local heating grids with lowered temperature as provider of balancing power), different targets for the improvement of the control will be investigated. One major target is an intelligent linking between the heat and electrical sector to demonstrate the opportunities of heating grids, as the investigated one, to balance the power grid.
\end{abstract}

Keywords: district heating system, model, Modelica, variable temperature, validation

\section{Introduction}

The German government agreed on the reduction of human-made greenhouse gas emissions to slow down the climate change (Bundesministerium für Umwelt, Naturschutz, Bau und Reaktorsicherheit, 2018) by focusing on the carbon dioxide emissions, which have by far the highest share based on carbon dioxide equivalents $\left(\mathrm{CO}_{2}\right.$ equivalents) (BMWi, 2018). Considering the application sectors power, transportation and heat, the share of the $\mathrm{CO}_{2}$ emissions by heat production accounts for approximate one third of the total $\mathrm{CO}_{2}$ emissions. District heating systems (DHSs) are considered cheap and easy way to integrate multiple renewable energy sources as well as to provide the linkage to the electricity grid.

Currently, DHSs are following different approaches to reduce the greenhouse gas emissions and therefore the environmental impact due to heating systems. On the one hand, the improvement of the system's efficiency and the integration of renewables or waste heat are subject to several research activities. To improve the system's efficiency, the temperature should be lowered, since the distribution losses highly depend on this temperature. Lowering the temperature is usually limited, because the majority of houses are already built. These houses usually need higher supply temperatures compared to new ones. On the other hand, current research on DHSs focusses on the integration into the overall energy system in order to reduce the environmental impact. One example of an innovative DHS which addresses both measurers, is described by Ramm et al. (2017). The system is located in Dollnstein (Germany) and operating since 2015. The scheme of this system is shown in Figure 1. Special emphasis is put on the house transfer stations, which include a heat exchanger, a heat pump and a buffer storage. The heating grid may supply the consumers with high temperatures by the heat exchanger or supply lowtemperature heat with $30^{\circ} \mathrm{C}$ while the decentralized heat pumps are used to provide heat at a desired level up to $60{ }^{\circ} \mathrm{C}$. Within the central heating station, multiple heat sources can be found. The system includes a solar thermal system, a peak boiler, a combined heat and power plant (CHP) as well as a $\mathrm{CO}_{2}$ heat pump (HP) utilizing close to surface geothermal heat by a well.

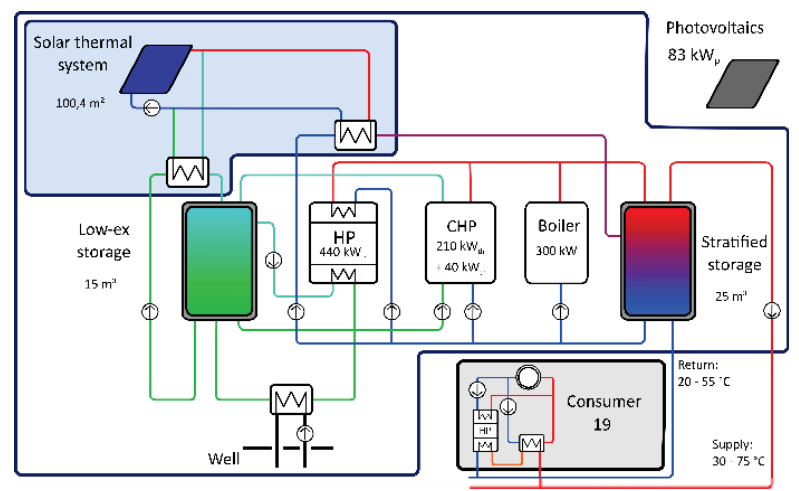

Figure 1. Schematic of DHS with variable temperatures operating in Dollnstein, Germany

The free and open-source programming language Modelica and the commercial software tool Dymola are widely used for the modelling of complex energy systems. The simulation of DHS in Modelica was done with different focus by numerous researchers.

A conventional district heating system, e.g. a DHS fed by a CHP, was simulated by Sangi et al. (2017). That work focusses on the development and application of exergy sensors for an automated exergy analysis tool based on Modelica. Bünning et al. (2018) investigated the novel approach of bidirectional low-temperature district energy systems. They investigated the performance of optimized operation for two test cases with other state of the art DHSs. They proved the concept by reduced energy costs, primary energy 
consumption and emissions. Del Hoyo Arce et al. (2018) created component models for the fast modelling of district heating and cooling networks to perform realtime simulations for the purpose of model predictive control. Their models were validated against other software tools.

\section{Methodology}

Within this paper, Modelica/Dymola is used to build a detailed simulation model of the heating station of the DHS in Dollnstein. These detailed models may also be referred to as digital twins, like done for the application in the field of building and equipment simulation by (Nytsch-Geusen et al., 2018), but mainly used in the field of production technology.

In the Modelica language, many free and open-source libraries are available. This work uses the Modelica Standard Library (MSL) and libraries based on the common core library IBPSA (International Building Performance Simulation Association). The IBPSA library was created within the project Annex 60 by the IEA EBC (International Energy Agency Energy in Buildings and Communities Programme) (Wetter, Fuchs et al., 2015) and is under further development within the IBPSA project. A new, more specialized library is created for the simulation of the DHS in Dollnstein. Main purpose is the use for this application, but the library will be created in an object-orientated way to ensure that the library can be easily used and adjusted for further simulations of low-temperature district heating systems (LTDHS). In this way, the library may constitute the basis for a district heating library at the Institute of New Energy Systems (InES). The scheme for the full model of the DHS is shown in Figure 2. The system is divided into four parts: Central heating station, heating grid, electricity grid and the superior control strategy. An additional block for evaluation purposes completes the model. The arrows indicate the direction of information flow. While the solid arrows represent the flow of physical quantities, which directly influence the receiving subsystem as well as control signals, the dotted lines illustrate the delivering of data like measurement data or set points. The thermal and control models will be developed with high detail and the electricity grid is represented by an ideal source and sink. Additionally, the model of the electricity grid should provide data about the electrical grid, e.g. the residual load. Within this paper, the implementation of the model of the central heating station is described. The model is implemented in an object-orientated manner, using a similar structure as shown in Figure 2. The pumps and valves are integrated within the thermal producer models. In addition, a single sub model represents the full solar thermal system marked with blue border and background (top left). All models contain low-order control algorithms, e.g. for pumps and valves. This kind of implementation together

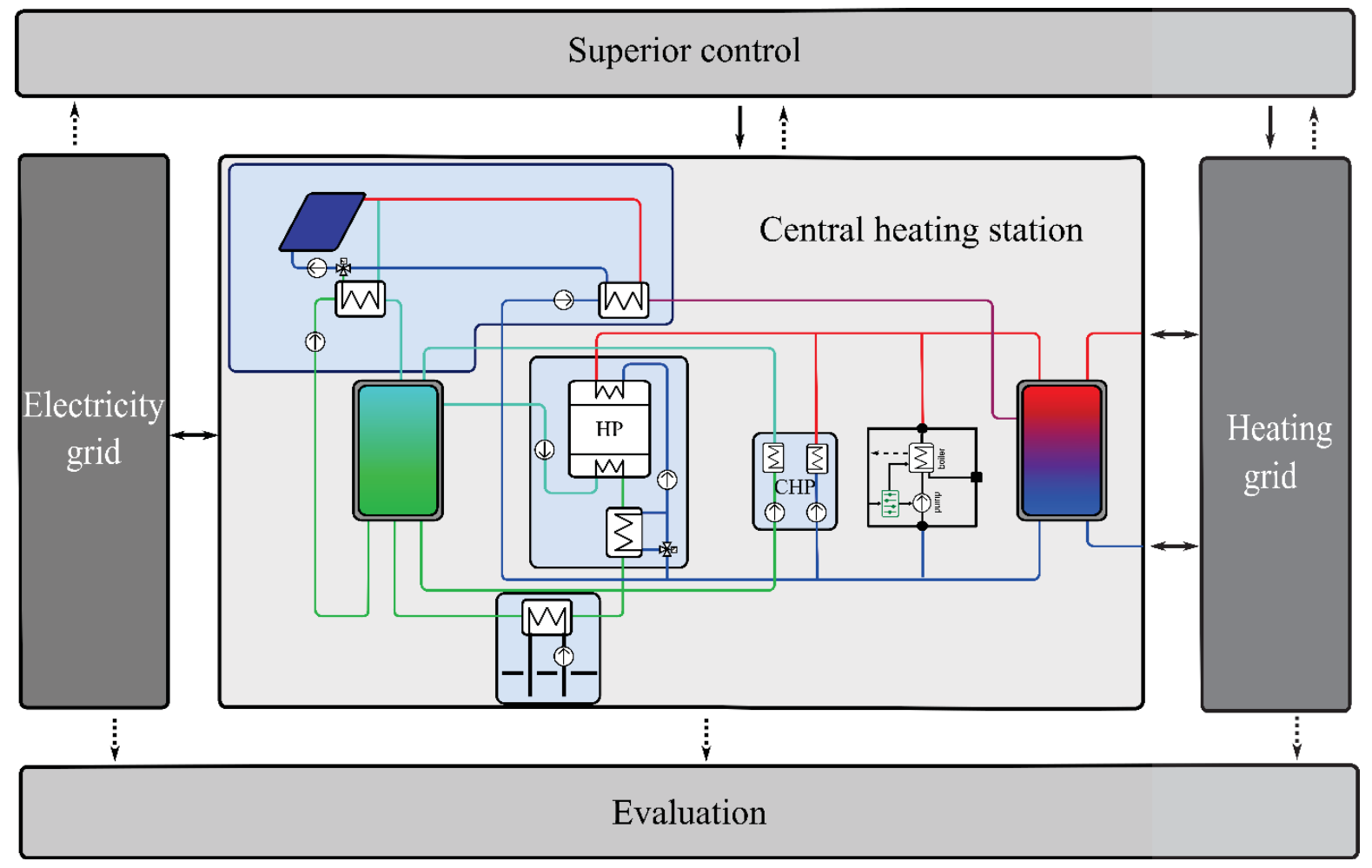

Figure 2. Schematic of system model. Solid arrows represent the flow of physical quantities which directly influence the receiving subsystem as well as control signals, the dotted lines constitute the delivering of data like measurement data or set points. 
with the use of base class models as shown e.g. in Figure 3 and Figure 4 allows for a quick exchange of parts of the system.

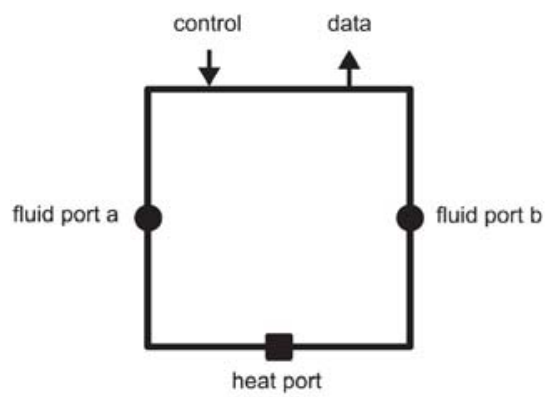

Figure 3. Basis model for a component (e.g. the boiler model)

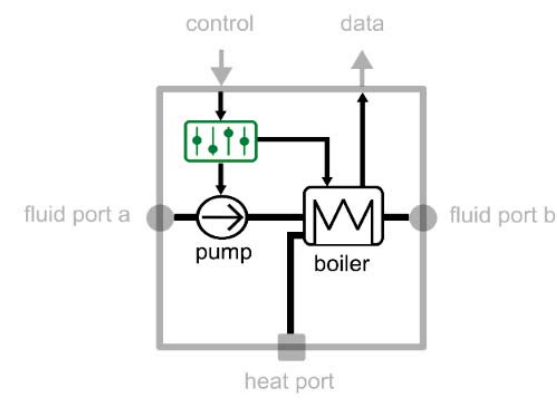

Figure 4. Full model for a component including secondary components and low-level control (e.g. boiler model)

The base class models include all mandatory interfaces to integrate the models to the system model. The boiler model shown in Figure 3 is an example and includes three ports with physical properties and several ports with further data. Due to the non-causal modelling approach of Modelica, the physical ports do not need an explicit direction of transferring information. The model has two fluid ports for entering and leaving heat transfer medium as well as one heat port to account for the heat transfer to the ambient. More information about the concept of physical connectors within Modelica can be found in Modelica Association (2017). The nonphysical connectors have an explicit direction of flow of information. A control signal is entering the boiler component and information for statistical and control purposes are leaving the component. The base class model is extended and additional information and sub models were added as shown in Figure 4. Components within the model can be exchanged for example by more or less detailed ones.

The component models of the heating station will be validated with measurement data from the actual operation mode. Temperatures, heat flow rates as well as electrical power and energy sums are used for the validation.

\section{Modelling}

The model is implemented in the programming language Modelica with the software Dymola (version 2019). The implementation is realized as shown at the scheme within Figure 2. On the one hand the model should be capable of simulating periods up to one year, within a reasonable time, to evaluate the systems performance for new operation approaches. One the other hand temperature changes as well as shut-on and shut-off behavior in minute resolution needs to be provided to balance the electrical grid on this scale. In this paper, the distinction between superior and lowlevel control is made. Low-level control means the control of e.g. pumps and valves by e.g. PID controllers. The superior control on the other hand decides based on the status of the system, e.g. the thermal storage tanks, whether heat production units are shut-on or shut-off.

The entire central heating station and the superior control in the simulation similar to the superior control of the real system are implemented. Both the district heating network as well as the electricity grid are represented as boundary conditions. The heat generators are modelled including the low-level control and additional aggregates like pumps and valves. Subsequently, the implementation of the main components is described briefly, including the boiler, the CHP, the heat pump, the solar thermal system and the thermal storage tanks. The efficiency depending on the operation temperatures is of major importance for the investigation of the system. This is especially true for the solar thermal system and the heat pump, since these components are highly dependent on the operation temperatures. Furthermore, the operation temperatures within the overall system are import to investigate and may change heavily during the year. Input data for the model are the out- and indoor ambient temperature as well as the solar radiation. Hitherto, the electricity grid as well as the heating grid are also input data.

\subsection{Combined heat and power plant}

The CHP from the manufacturer Riemag is powered by liquid gas and extended with an additional hydraulic cycle, which uses the condensing energy as well as the heat from the exhaust air coming from the case of the CHP. The first cycle feeds the stratified storage while the second one provides the heat to the low-temperature storage. The model also has one input to control the start-up/shut-down of the model as well as its behavior under partial load. The CHP unit is a model from the BuildingSystems library (Nytsch-Geusen, et al., 2016). The model is based on two characteristic curves, one for the electrical power and one for the heating. These curves are used for the calculation of the fuel demand. While the internal pump of the CHP is controlled to maintain a certain supply temperature, the pump for the condensing cycle just switches on and off with respect 
to the operation of the CHP and the temperature inside the low-temperature storage. The heat transfer to the additional hydraulic circuit is considered by a constant heat flow rate, as long as the CHP is in operation. The heat flow rate was determined by measurement data. The heat transfer is only possible until a certain temperature of the fluid. The pump of the second hydraulic cycle is only operational when the lowtemperature tank has a maximum temperature below $21{ }^{\circ} \mathrm{C}$.

\subsection{Heat pump}

At the Dollnstein system, a heat pump of the type thermeco2 HHR 520-3(345) with additional internal heat exchanger and $135 \mathrm{~kW}_{\mathrm{el}}$ nominal input, distributed equally on three compressors, is installed. The set supply temperature varies over time.

The HP model is based on a HP model out of the IBPSA library. The HP in the real system has three compressors. It is assumed that the efficiency does not depend on the number of compressors that are in operation as long as they work at full load. The efficiency at partial load can be described by an arbitrary polynomial function. Therefore, a new model including three of the aforementioned HP models in parallel was set up. The main ports of the model are four fluid ports, two at the source and two at the sink as well as a control signal, which can vary between 0 and 1 . In this context one third means one compressor at nominal load. The effectiveness at nominal condition can be defined by the Carnot efficiency and a reducing factor or by giving a coefficient of performance (COP) at nominal conditions.

Moreover, the model is used with a given COP at nominal conditions, which was taken from the manufacturer data. For these nominal conditions, the manufacturer claims an electrical demand of $124 \mathrm{~kW}$. The electrical demand of real HP is changing by the variation of the operation point. The model instead has the same electrical demand in every operation point. Therefore, the electricity demand of the model was adjusted to the measurement data from $124 \mathrm{~kW}$ to $132 \mathrm{~kW}$.

The main inputs for the energetic calculations are the temperatures and temperature differences at the heat exchangers as well as the nominal COP and the already mentioned electrical power consumption. The dynamic behavior is described by the capacity of fluid within the heat exchangers, which are bounded to the nominal mass flow rates.

\subsection{Boiler}

The boiler model has four important interfaces: two fluid ports, one heat port and one control input. The model consist of the control, a pump and the actual boiler model, which is part of the Buildings library (Wetter, Bonvini et al., 2015). The actual control of the boiler is a two-point control depending on the storage temperature. During run-time, the boiler runs with fixed power. The pump is also operated on a fixed power and switches on and off together with the boiler, but delayed. A short description of the actual boiler model can be found within the model description of the Buildings library. Hitherto, a constant efficiency of the boiler is chosen, because the gas consumption from the boiler on its own cannot be determined yet.

The losses to the surrounding can be included by the efficiency curve of the boiler model or additionally added by connecting the heat port to the ambient. The dynamic behavior is determined by the heat capacity of the boiler itself as well as the fluid volume inside the boiler and the heat losses.

In this modelling step, the parameters were taken from the manufacturer data for the boiler type Buderus SB 625-310 (289.9 kW).

\subsection{Solar thermal system}

The solar thermal system consists of the hydraulic collector cycle including the collectors, a pump, a threeway-valve and two heat exchangers. The solar thermal collectors are flat plate collectors from the manufacturer ratiotherm of type $R A$ 251-4. The two heat exchangers supply the two different thermal storages on different temperature levels with heat.

The collector model was chosen from the BuildingSystems library. This model is a general multinode model. Due to lower computational effort, the solar collectors are aggregated in one model. The main parameters are the coefficients to calibrate the efficiency curve. Additional parameters are the absorber volume and heat capacity. All parameters are available from the manufacturer data. During summer operation, the solar collectors only feed the stratified storage. The feeding during winter operation depends on the temperature within the low-exergy storage. Until a certain threshold temperature inside the low-temperature storage, the solar heat is fed to that storage. The set supply temperature of the solar thermal system is also dependent on the temperature of the storage to be fed.

\subsection{Thermal storage tanks}

The central heating station includes two thermal storage tanks with volumes of $15 \mathrm{~m}^{3}$ and $25 \mathrm{~m}^{3}$. The larger one is the stratified storage that feeds the grid while the buffer storage at lower temperature feeds the source of the heat pump.

For both storages, the storage model from the BuildingSystems library is used. The model is a onedimensional model that takes the buoyancy by a simple thermal model into account. Mixing due to in- and outflowing streams is neglected. The necessary data to parametrize both heat storages is taken from manufacturer information. The stratified storage includes temperature measurements at five different 
levels of height. The discretization within the model is done in a way that the temperature sensors are located in different segments. The buffer storage is represented only by five elements and includes three temperature sensors.

\subsection{Superior control}

The actual superior control is primarily based on the temperatures within the storages. The aggregates switch on and off due to the temperatures within the stratified storage. Minimum operation times and down times are not taken into account yet. The set temperature for the grid is given as an input table and relates both to the outdoor ambient temperature and the heat demand. The superior control is also able to control the decentralized heat pumps and may take different temperatures at the consumers into consideration. However, this is not used yet, as the heating grid only serves as boundary condition.

\section{Model validation}

The validation of the model is described subsequently. The model was validated quantitatively in terms of energy in- and output, e.g. thermal, electrical and fuel consumption on a monthly scale. Additionally, the dynamic behavior of the component models was evaluated in a qualitative way. Mass flow rate, the supply temperature, the provided heat and consumed electrical power of the HP were studied for one cycle of operation (shut-on and shut-off). In addition, the full period of time is taken into account by analyzing the root mean square error (RMSE) between the simulation and measurement. The RMSE is discussed and described by Chai and Draxler (2014). The discrete form is shown in equation (1). The formula describes the square root of the average of the squared differences at certain evaluation points. The quantity is the same as the quantity of the data.

$$
R M S E=\sqrt{\frac{1}{n} \sum_{i=1}^{n}\left(x_{\mathrm{sim}}-x_{\mathrm{meas}}\right)^{2}}
$$

For evaluation purposes, the non-discrete notation was implemented as displayed in equation (2).

$$
R M S E=\sqrt{\frac{1}{T} \int_{t=1}^{T}\left(x_{\text {sim }}-x_{\text {meas }}\right)^{2}}
$$

An evaluation for the different components can be found in the following sub-sections.

If available, recorded control data from superior control were used as inputs for testing the components. Otherwise, the control signal was derived from the measurement data. The evaluation is summarized in the end of the section and energy wise displayed in Table 1.

\subsection{Combined heat and power plant}

The operation of the CHP is investigated for the period from $1^{\text {st }}$ March to $31^{\text {st }}$ May 2018. For the observed months, the CHP was about 1000 hours in operation and fed 164.5 MWh heat to the stratified storage as well as 12.6 MWh to the low-temperature storage. The simulation model fed $163.0 \mathrm{MWh}$ to the stratified storage, which means an error of only $0.9 \%$ (see Table 1 ), but $32 \mathrm{MWh}$ to the low-temperature storage. The resulting difference occurs because the model also supplies the low-temperature storage within summermode, while the real CHP does not. This functionality needs to be added to the model.

Figure 5 shows different values for one operation cycle in March 2018. The control signal is always plotted in the sub-plots below.

The left sub-figure shows the electrical power of the system. Negative values indicate that the CHP is running and electrical power is fed to the public grid. Positive values indicate a supply of the system from the public electricity grid.
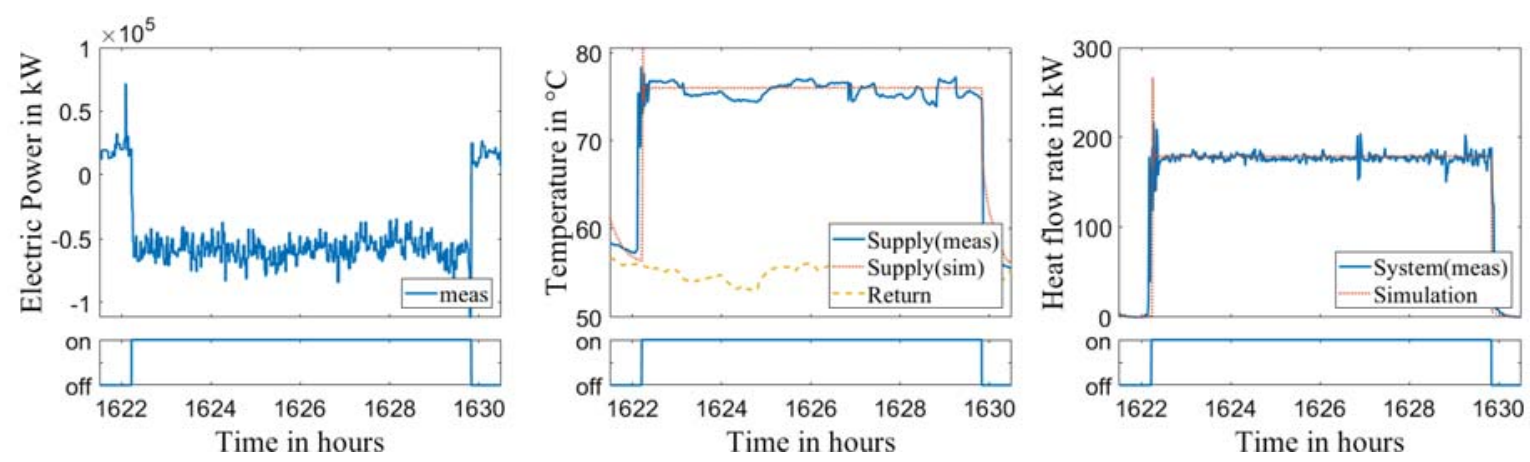

Figure 3. Validation for the CHP operation - one operation cycle. Left sub-figure shows the electrical power of the system. Sub-figure in the middle displays supply and return temperatures for the conventional and the condensing cycle. The right sub-figure shows the heat flow rates for the conventional as well as the condensing cycle. Below the sub-figures, the control signal is plotted. 
The real CHP does not have a very stable control. Due to that reason, both the mass flow rate and the supply temperature (middle sub-plot) are strongly varying during operation. As a result, the heat flow rates (right sub-figure) strongly vary during operation too. This is especially true during times without the utilization the condensing cycle. The control of the model is much more stable compared the real control. The supply temperature (middle sub-figure) and provided heat flow rate (right sub-figure) are almost constant during operation. Only after switching on the unit, the supply temperature shows a peak (Figure 5middle sub- plot) that also leads to a peak in the supplied heat flow rate (Figure 5 - right sub-plot). The RMSE for the heat flow rate is $20.4 \mathrm{~kW}$ and $4.2{ }^{\circ} \mathrm{C}$ for the temperature. This means noticeable differences over the course of time, but a big share of these differences is due to the unstable control of the real CHP. Since the aim is not to reproduce this behavior, this value itself has only little significance. Therefore, the allover heat energy (Table 1) and the graphs shown in Figure 5 are more meaningful in this case. Although there are some differences between model and reality, the allover validation results show that the CHP model meets the requirements of the simulation analysis formulated in section 3 .

\subsection{Heat pump}

The observed operation period for the heat pump lasts from $1^{\text {st }}$ January to $30^{\text {th }}$ April 2018. During the summer mode, the heat pump is not operating. Within the four observed months, the heat pump is approximately 2000 hours in operation, mostly with one compressor, sometimes utilizing a second compressor, but never using all three compressors. The inlet temperature at the sink needs to be maintained below $50^{\circ} \mathrm{C}$, because higher temperatures lead to problems with the heat pump operation. An additional heat exchanger provides reliability of operation also during the winter period, when higher return temperatures in the grid occur. During summer, this is not an issue and the return temperature may drop down to $20^{\circ} \mathrm{C}$. The supply temperature of the grid during winter usually varies between $60^{\circ} \mathrm{C}$ and $80^{\circ} \mathrm{C}$. The source temperature ranges between $10^{\circ} \mathrm{C}$ and $23^{\circ} \mathrm{C}$ while the temperatures usually range around $11^{\circ} \mathrm{C}$, which is in the range of the supply temperature of the well. The source temperature is in the higher range when the low-temperature storage was charged by the solar thermal system or the condensing cycle of the CHP. The temperatures of the source are not displayed in Figure 6.

Figure 6 shows different values for one operation cycle in January. The control signal is always plotted below the other graphs. While the real HP consumes an electricity amount of $128.7 \mathrm{MWh}$, a minor deviation of less than $1 \%$ between the real HP and the model can be observed as shown in Table 1. The left sub-plot displays the measured and simulated electricity consumption, which match each other very well. In the middle figure, the supply and return temperatures are shown. After switching on the HP, the model needs a certain time to reach stable control as the control of the pump is not optimal parametrized. Adjustments within the low-order control need to be done to achieve a more stable start-up behaviour. While the supply temperature fits during operation, there is a significant deviation during the nonoperation time. This is acceptable, since the thermal behaviour during non-operation time is of minor importance as long as the influence on the operation time is limited.

The graphs in the right figure show the effective heat flow rate for the heat, which is transferred to the fluid, i.e. the heat flow rate provided by the heat pump system. The heat pump system includes the additional heat exchanger, shown in Figure 1. Therefore, the heat flow rate provided by the heat pump is reduced by the heat flow transferred between the heat exchanger and the source of the heat pump. The systems efficiency is highly dependent on the set temperature of the valve, which ensures that the return temperature directly at the heat pump stays below the threshold. The simulated heat for the displayed flow rate is slightly lower than the measurement data. This holds true for the most of the
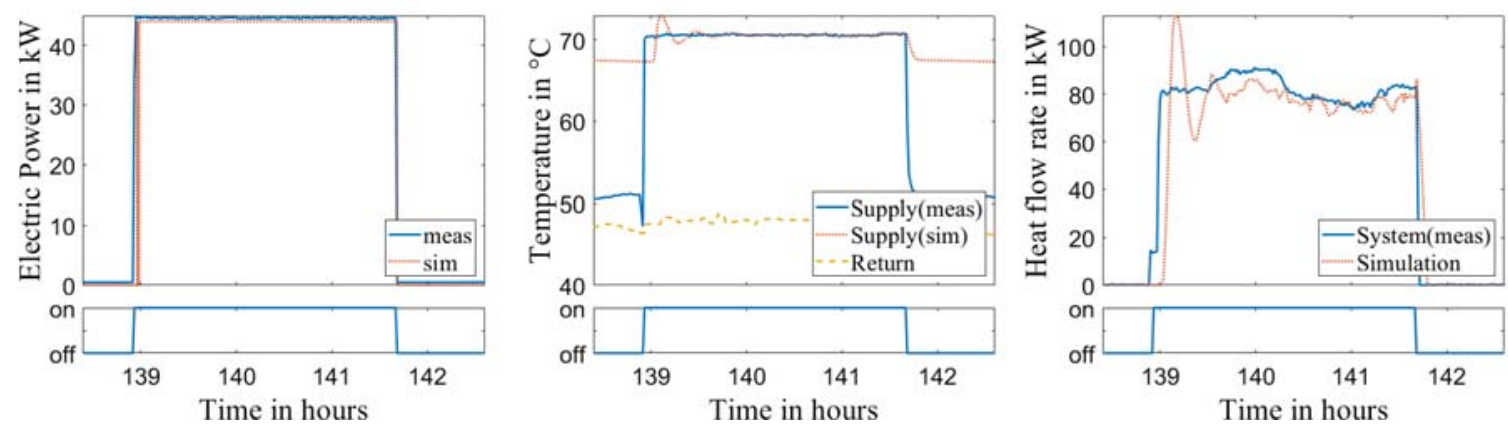

Figure 4. Validation for the HP operation - one operation cycle. Left sub-figure displays the electrical power input. Middle figure displays the supply and return temperature for the sink of the HP. Right sub-figure shows the heat production of the heat pump. Below the sub-figures the control signal is plotted. 

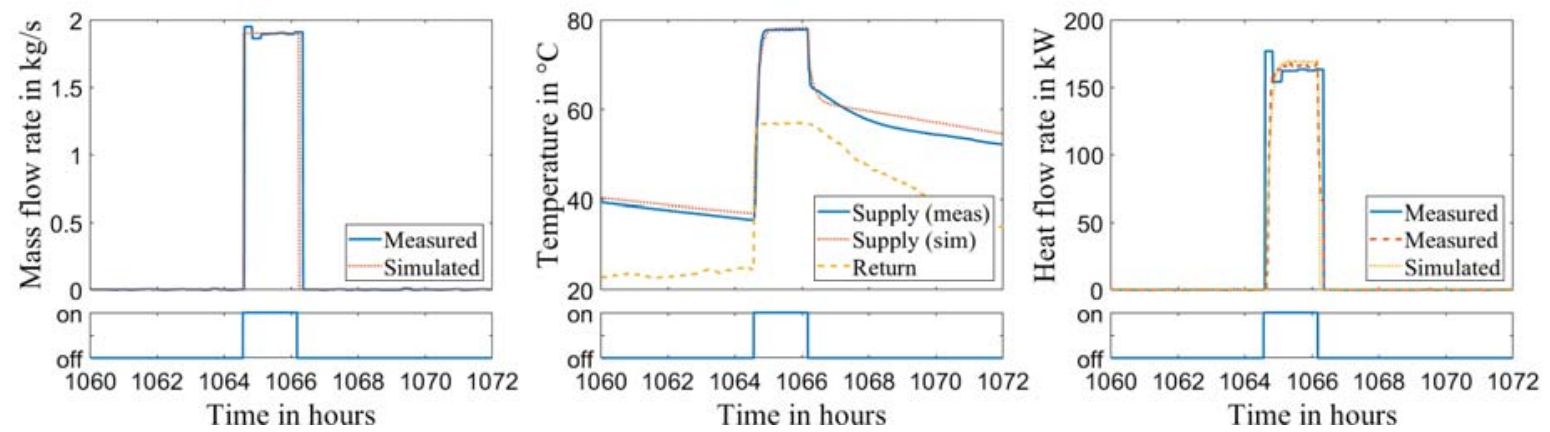

Figure 5. Validation for the boiler operation - one operation cycle. Left sub-figure shows the mass flow rate. The middle sub-figure displays supply and return temperatures. The right sub-figure show the provided heat flow rate. The control signal is plotted below the sub-figures

operation cycles, but the deviation changes, resulting in a deviation of produced heat of $10.7 \%$. In the future work, the calibration of the HP model will be further pursued.

\subsection{Boiler}

For the testing of the boiler model, the recorded operation signal from the superior control was used as an input for the simulation model. The actual measured temperature constitutes the boiler's fluid inlet temperature. The validation period is the time from $1^{\text {st }}$ February to $30^{\text {th }}$ of March 2018. The boiler's operating periods lasted between 0.5 and more than 4 hours. Within 34 hours of operation, the boiler generated a heat amount of $5.43 \mathrm{MWh}$ that means an average heat output of $160 \mathrm{~kW}$. During summer, the boiler is not in operation. The heat output in the model is $5.5 \mathrm{MWh}$, which amounts to an error of $0.9 \%$ (Table 1 ).

The dynamics of the model compared with the measured data are shown in Figure 7. In the model as well as in reality, sensors measure the temperature directly after the boiler. Below the main figures, the recorded operation time of the boiler is shown. The left figure shows the measured and simulated mass flow rate. The assumption of $1.9 \mathrm{~kg} / \mathrm{s}$ within stable operation meets the measurement data $(1.85 \mathrm{~kg} / \mathrm{s}$ to $1.95 \mathrm{~kg} / \mathrm{s})$ quite well. A comparison of the supply temperature from simulation with the measurement data shows, that these match very good during operation, but shows different results when the boiler is turned off. After turning off, the pump has a shutdown delay of three minutes. During this time, there is a strong drop in the supply temperature in the measurement data and the simulation. In the following time, the temperature drop in the simulation is slower compared to the measurement. Since both the mass flow rate as well as the temperatures fit during simulation, a high degree of correlation can be observed for the heat flow rate, too (Figure 7- sub-plot right). The RMSE of the heat flow rate for the full operation time is $11.6 \mathrm{~kW}, 2.2^{\circ} \mathrm{C}$ for the supply temperature and $0.15 \mathrm{~kg} / \mathrm{s}$ for the mass flow rate. Taking all these values in consideration, the boiler model meets the measurements and requirements very well.

The efficiency e.g. the gas consumption could not be validated yet, because there is no data from that sensor yet.

\subsection{Solar Thermal System}

The collector model was parametrized by the data sheet of the real collector. The simulation results meet the steady-state performance according to the data sheet. The full solar thermal system was not validated yet, but will be processed in following studies.
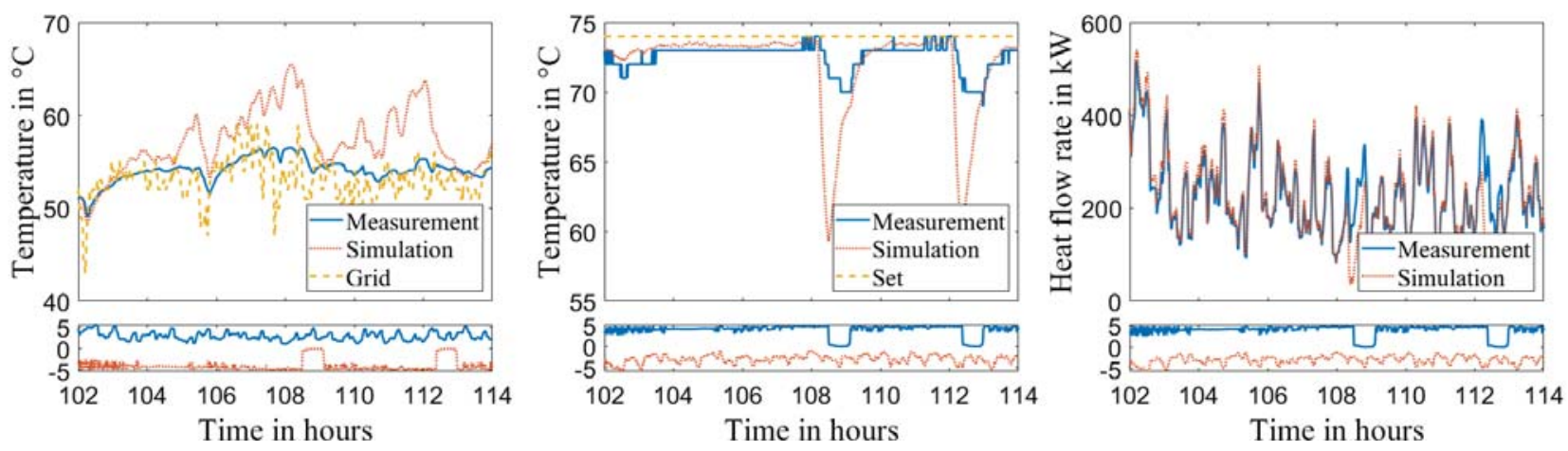

Figure 6. Validation for the utilization of the stratified storage - Period of 12 hours in January. Left sub-figure shows the temperatures of the fluid leaving the bottom of the storage to enter the return of the producers and from the return inflowing from grid. The middle sub-figure displays the supply temperature for the heating grid. The right sub-figure shows the heat flow rate leaving the storage to the district heating grid. The entering (positive) and leaving (negative) mass flow rates are plotted below the sub-figures. 


\subsection{Thermal storage tanks}

The validation period for the storage tank is from $1^{\text {st }}$ January to $1^{\text {st }}$ February 2018. Figure 8 shows 12 hours of the validation period. To perform the validation the inflowing mass flow rates with temperatures as well as the indoor ambient temperature are described. For the outflowing fluid, only the mass flow rate is given and the temperature is part of the evaluation. The temperatures of the outgoing mass flows for the supply of the heating grid as well as the return to the heat generators are import for the system's behavior. In addition, the temperatures at the temperature sensors inside the storage are important for the superior control, because the heat producers are shut on and off due to these temperatures.

Over the course of the month, the storage supplied to the grid amounts to $176.8 \mathrm{MWh}$ of heat. The model supplied $175.3 \mathrm{MWh}$ and meets the measurement data with an error of $0.8 \%$ (see Table 1 ).

In the left sub-figure the measured and simulated return temperatures to the heat producers, outflowing from the stratified storage at the bottom, are plotted together with the temperature of flow entering from the grid. In the sub-figure below, the mass flow rates, leaving and entering at the bottom of the heat storage are shown. The outflowing mass flow rate is negative (flow to the producers) and the entering one (flow from the grid) is positive. For most of the time, the simulated temperature is higher than the measured one. During periods without operation of heat producers, the temperatures approach each other. The temperature deviation is significant, thus the behavior needs to be investigated more in detail. The temperature difference at the bottom of the storage needs to be reduced, since this temperature is relevant for the entire system. The sub-figure in the middle displays the measured and simulated temperature at the top of the storage, supplying the grid as well as the set-temperature of the supply. To maintain the supply temperature the colder return from the grid can be mixed with the supply from the storage. This ensures that the supply has no higher temperatures than necessary.

The measured and simulated grid supply temperatures match well. This holds true for the most of the observed period. Nevertheless, it can also be realized that the temperature in the model changes faster and that there are periods with big differences. These periods typically occur when the temperature at the top of the heat storage is dropping. This happens in case that the producers do not supply the heat storage anymore while the storage still feeds the grid. The drop in the model is more drastic. In the right sub-plot, the influence on the supplied heat flow rate is displayed. It can be seen that measurement and simulation match well for most of the time, but the differences occur at similar times as for the supply temperature. The simulated heat flow rate is lower than the measured one during phases of no heat production. As already mentioned in the beginning of this section, the overall heat supply of the model from the storage to the grid meets the measurement data very well, so that the influence of the differences in the heat flow rates at certain times is not significant for the evaluation of the energy balance.

\subsection{Superior control}

The superior control for the operation of the central heat production units was implemented. For the most cases, the real controller and the model controller show the same behaviour, but slight time shifts occur.

\subsection{Heating Central}

The model of the entire heating central contains the models validated in the sub-sections before. For the central heating station, the efficiency of the whole system is most important and will be evaluated. Therefore the incoming and outgoing energy flows will be used.

Table 1. Evaluation of produced heat and energy demand for observation periods (CHP: $1^{\text {st }}$ January to $30^{\text {th }}$ April 2018 , Heat 1 feeding to stratified storage, Heat 2 feeding to low-temperature storage; HP: $1^{\text {st }}$ January to $30^{\text {th }}$ April 2018; Boiler: $1^{\text {st }}$ February to $30^{\text {th }}$ March 2018; Storage: $1^{\text {st }}$ January to $1^{\text {st }}$ February 2018)

\begin{tabular}{|l|l|r|r|c|}
\hline Component & Heat/ Fuel/Electricity & Energy (Measurement) & Energy (Simulation) & $\begin{array}{c}\text { Rel. error } \\
{[\%]}\end{array}$ \\
\hline \multirow{2}{*}{ CHP } & Heat 1 & $164.5 \mathrm{MWh}$ & $163.0 \mathrm{MWh}$ & -0.9 \\
\cline { 2 - 5 } & Heat 2 & $12.6 \mathrm{MWh}$ & $32.0 \mathrm{MWh}$ & \\
\hline \multirow{2}{*}{ HP } & Heat (effective) & $236.8 \mathrm{MWh}$ & $211.4 \mathrm{MWh}$ & -10.7 \\
\cline { 2 - 5 } & Electricity & $128.7 \mathrm{MWh}$ & $127.6 \mathrm{MWh}$ & -0.9 \\
\hline \multirow{2}{*}{ Boiler } & Heat & $5.4 \mathrm{MWh}$ & $5.5 \mathrm{MWh}$ & +0.9 \\
\hline Storage & Heat (grid supply) & $176.8 \mathrm{MWh}$ & $175.3 \mathrm{MWh}$ & -0.8 \\
\hline
\end{tabular}




\subsection{Discussion}

The component models show a good correspondence between simulation and reality. The superior control sends operation signals to the production units. These are mainly dependent on the storage temperatures of the stratified storage. The part of the superior control that is related to the grid operation will be implement in the next step.

The heat producers and the superior control are implemented, but for some operation conditions, significant differences occurred. One of these is the CHP within during the summer period. At this time, the real CHP does not provide any heat to the lowtemperature storage. This needs to be taken into account and is the reason, why there is a significant difference in the heat amount supplied to the low-temperature storage between measurement and simulation. The delivery of heat by the HP is very sensitive with respect to the mixing temperature at the sink inlet. The mixing of the inlet temperature as well as the implementation of the of the heat pump characteristics need adjustment to reduce difference between the simulation and measurement results for the heat pump.

To observe the system's efficiency with respect to fuel some, adjustments for the consumption of fuel have to be made. Furthermore, the power demand of the pumps within the system must be taken into account. Additionally, minimum operation and shut-down times should be considered, since these are limiting future control strategies.

\section{Conclusion}

The central heating station of the DHS was implemented within Modelica with all major units and additional components like pumps and valves. The model is appropriate for the detailed simulation of the central heating station and investigation of new superior control strategies.

The models of heat generators were implemented and validated by the measurement data from the real system. The heat supply shows a high degree of correlation. Nevertheless, there is potential for improvement. The efficiencies with respect to the fuel needs to be evaluated. In addition, improvements for the low-level control could be done to improve the stability and computational performance. Additionally the model of the heat pump should be further improved. On the one hand, the model itself could be improved, one the other hand the parametrisation of model could be improved. Since the temperatures within the heat storages are of major importance for the control of the system, occurring temperature differences should also be investigated more in detail.

Completing the validation of the system, will be the next step. Especially the solar thermal system and the gas consumption of the CHP and boiler need to be adjusted to measurement data. Additionally, the power consumption for the pumps needs to be added to evaluate the overall performance of the heating station and the subsystems.

The energy amounts for the whole period are used for the evaluation, since these are of major importance for evaluating the efficiency for the whole year. However, it needs to be secured that the operation for different conditions meet the real systems behaviour.

To model the entire system, a model of the heating grid including the consumers' needs to be added. This model extension is necessary to improve the entire control system including the control of the circulator pumps and the use of the distributed HPs.

\section{Acknowledgements}

The authors are grateful to Bundesministerium für Wirtschaft und Energie (BMWi), which finances the project NATAR (Local heating grids with lowered temperature as provider of balancing power; grant number: 03ET1425A), the founding agency Project Management Jülich (PtJ) as well as all project partners.

\section{References}

BMWi (2018). Höhe der Treibhausgasemissionen in Deutschland nach Gas im Jahresvergleich 2000 und 2016 (in Millionen Tonnen CO2-Äquivalent). [Online]. Available at https://de.statista.com/statistik/daten/studie/ 311861/umfrage/menge-der-treibhausgasemissionen-nachgasen-in-deutschland (Accessed 2 October 2018).

Bundesministerium für Umwelt, Naturschutz, Bau und Reaktorsicherheit (2018). Klimaschutz in Zahlen: Sektorenziele 2030. [Online]. Available at ), www.bmub.bund.de (Accessed 18 October 2018).

Bünning, F., Wetter, M., Fuchs, M. and Müller, D. (2018). Bidirectional low temperature district energy systems with agent-based control: Performance comparison and operation optimization. Applied Energy, vol. 209, pp. 502515. doi:10.1016/j.apenergy.2017.10.072

Chai, T. and Draxler, R. R. (2014). Root mean square error (RMSE) or mean absolute error (MAE)? - Arguments against avoiding RMSE in the literature. Geoscientific Model Development, vol. 2, 1247-1250. doi: 10.5194/gmd7-1247-2014

del Hoyo Arce, I., Herrero López, S., López Perez, S., Rämä, M., Klobut, K. and Febres, J. A. (2018). Models for fast modelling of district heating and cooling networks. Renewable and Sustainable Energy Reviews, vol. 82, pp. 1863-1873. doi: 10.1016/j.rser.2017.06.109

Modelica Association (2017) Modelica - A Unified ObjectOriented Language for Systems Modeling: Language Specification.

Nytsch-Geusen, C., Kaul, W. and Kharraz, S. (2018). Der digitale Zwilling in der energetischen Gebäude- und Anlagensiulation. BauSIM2018 - 7. Deutschösterreichische IBPSA-Konferenz. Karlsruhe, pp. 311-318.

Nytsch-Geusen., C., Banhardt, C., Inderfurth, A. and Mucha, K. (2016). Buildingsystems - Eine modular hierarchische 
Modell-Bibliothek zur energetischen Gebäude und Anlagensimulation. in Grunewald, J. (ed) CESBP Central European Symposium on Building Physics/BauSIM 2016: Dresden, Germany, September 14 - 16, 2016. E-Book of Proceedings, Stuttgart, Fraunhofer IRB Verlag.

Ramm, T., Hammel, C., Klärner, M., Kruck, A. and Schrag, T. (2017). Energy storage and integrated energy approach for district heating systems. Energy Procedia, vol. 135, pp. 391-397. doi: 10.1016/j.egypro.2017.09.515

Sangi, R., Jahangiri, P., Thamm, A. and Müller, D. (2017). Dynamic exergy analysis - Modelica ${ }^{\circledR}$-based tool development: A case study of CHP district heating in Bottrop, Germany. Thermal Science and Engineering Progress, vol. 4, pp. 231-240. doi: 10.1016/j.tsep.2017.10.008

Wetter, M., Bonvini, M., Nouidui, T. S., Tian, W. and Zuo, W. (2015). Modelica Buildings Library 2.0. Proceedings of BS. Hyderabad, India, Dec. 7-9, 2015.

Wetter, M., Fuchs, M., Grozman, P., Helsen, L., Jorissen, F., Lauster, M., Müller, D., Nytsch-Geusen, C., Picard, D., Sahlin, P. and Thorade, M. (2015). IEA EBC Annex 60 Modelica Library - An International Collaboration to Develop a Free Open-Source Model Library for Buildings and Community Energy Systems. Proceedings of BS. Hyderabad, India, Dec. 7-9, 2015, pp. 395-402. 